University of Nebraska - Lincoln

DigitalCommons@University of Nebraska - Lincoln

$1-17-2006$

\title{
Orisaltata, a new genus of flea beetles from the Oriental Region (Coleoptera: Chrysomelidae)
}

Kaniyarikkal Divakaran Prathapan

Alexander S. Konstantinov

Follow this and additional works at: https://digitalcommons.unl.edu/usdaarsfacpub

This Article is brought to you for free and open access by the U.S. Department of Agriculture: Agricultural Research Service, Lincoln, Nebraska at DigitalCommons@University of Nebraska - Lincoln. It has been accepted for inclusion in Publications from USDA-ARS / UNL Faculty by an authorized administrator of DigitalCommons@University of Nebraska - Lincoln. 


\title{
Orisaltata, a new genus of flea beetles from the Oriental Region (Coleoptera: Chrysomelidae)
}

\author{
K. D. PRATHAPAN ${ }^{1} \&$ A. S. KONSTANTINOV ${ }^{2}$ \\ ${ }^{1}$ Department of Entomology, Kerala Agricultural University, Vellayani P. O., Trivandrum - 695 522, Kerala, \\ INDIA, prathapankd@gmail.com \\ ${ }^{2}$ Systematic Entomology Laboratory, PSI, Agricultural Research Service, U. S. Department of Agriculture, c/o \\ National Museum of Natural History, MRC 168 Washington, DC 20560, U. S. A., akonstan@ sel.barc.usda.gov
}

\begin{abstract}
A new genus, Orisaltata, with the type species Aphthona azurea Jacoby (the only known species) from the Oriental Region is described and illustrated. Comparative notes and host plant information are provided. Aphthona babai Kimoto is synonymized with Orisaltata azurea.
\end{abstract}

Key words: Chrysomelidae, new genus, synonymy, Oriental Region

\section{Introduction}

A revision of the Aphthona Chevrolat of the Oriental Region necessitated removal of 19 incorrectly placed species from the genus (Konstantinov \& Lingafelter, 2002). Two congeneric species, Aphthona azurea described by Jacoby (1896) from Myanmar and A. babai described by Kimoto (2000) from Thailand, were placed under incertae sedis in the above revision because they do not share any synapomorphy with Aphthona. Further studies of additional material collected in India and Thailand revealed that these species are synonymous and belong to a new genus,which is described below. Dissecting techniques and terminology follow Konstantinov (1998). The beetles are deposited in the following collections: National Museum of Natural History, Smithsonian Institution, Washington, D. C. (USNM); Museum of Comparative Zoology, Cambridge, Massachusetts, USA (MCZC); University of Agricultural Sciences, Bangalore, India (UASB), Kitakyushu Museum and Institute of Natural History, Kitakyushu, Japan (KMHJ), and the personal collection of the senior author (PKDC). 
Description. Body of medium size, length 2.20 to $2.80 \mathrm{~mm}$, width 1.38 to $1.68 \mathrm{~mm}$, oblong, moderately flat in lateral view. Color metallic dark blue, antenna, labrum, tibia, tarsus, and scutellum black, sternum and femur black with bluish tint. Head hypognathous, flat in lateral view (Fig. 2). Frons and vertex separately form slightly convex lines in lateral view, intersection of vertex and frons appear notched in lateral view. Vertex slightly convex, finely punctate. Supraorbital pore well developed, circular, surrounded by shallow groove deepening anteromesally, four minute setiferous pores present in shallow groove. Antennal callus well developed, obliquely trapezoidal, length being slightly less than two times width, anterior end acutely triangular and entering into interantennal space. Antennal callus higher near post callinal sulcus rather than near antennal socket. Midfrontal sulcus well developed, wide; suprafrontal sulcus distinct, well developed; supraorbital sulcus poorly developed; supracallinal sulcus well developed, nearly straight, deep. Orbital sulcus well developed. Subgenal suture well developed along base of mandible. Orbit narrow, slightly narrower than transverse diameter of antennal socket. Interantennal space 0.42 times as wide as transverse diameter of eye and 0.94 times as wide as transverse diameter of antennal socket. Frontal ridge acutely narrowed between antennal sockets, widening anteriorly. Anterofrontal ridge well developed, relatively high, not separated from frontal ridge. Labrum with four setiferous pores arranged in a transverse row, with a pair of sensilla on either side of middle pair of setae. Apical margin with five short sensilla on each side. Torma longer than width of labrum. Mandible with four denticles besides a serrulate cutting edge. Labium with three palpomeres per palpus, third palpomere longest. Maxilla with lacinia wider and longer than galea. Sensilla patch of apical maxillary palpomere longer than wide, consisting of six embedded sensilla. Penultimate palpomere slightly wider than long. Frontoclypeal suture with a row of long setae, medially discontinuous. Antenna filiform, reaching middle of elytra or slightly beyond. First antennomere slightly shorter than twice the length of second; third thinner than second, distinctly longer than second; third and fourth antennomeres subequal; fourth and fifth subequal. Eyes laterad, inner margin weakly concave, transverse diameter 0.31 times vertical diameter.

Pronotum 1.60 times wider than long, without impressions, sides indistinctly curved, widely explanate. Lateral margins nearly parallel to each other. Anterolateral callosity about as long as 1/4 of lateral margin including anterolateral callosity, with pore situated at posterodorsal face; seta slightly shorter than length of lateral margin, dorsally directed. Anterolateral callosity convex, anteriorly higher than posteriorly, with obtuse denticle at pore. Posterolateral callosity slightly protruding, pore situated laterally, seta slightly shorter than length of lateral margin, laterally directed. Posterior margin weakly bisinuate.

Anterior coxal cavity open. Intercoxal prosternal process moderately wide, posteriorly widened, flat, apical margin convex, projecting beyond coxa. Distance between proximal 
margin of prosternum to coxal cavity 0.12 times as long as distance from proximal margin of prosternum to end of intercoxal prosternal process. Minimum width of intercoxal prosternal process 3.2 times minimum distance from anterior margin of prosternum to coxal cavity. Proendosternites well developed, facing each other, top nearly rounded with unsclerotised angulate apical portion. Visible part of mesoscutellum flat, triangular, broader than long with broadly rounded apex, extremely minutely punctate. Longitudinal diameter of mesocoxal cavity 3.10 times as long as mesosternum above mesocoxal cavity. Mesepimeron and mesepisternum forming outer side of mesocoxal cavity. Mesosternal intercoxal process 1.97 times as wide as prosternal intercoxal process, slightly concave on top, posterolateral corners acutely angulate. Mesendosternite narrower at base than middle, narrowing apically, not connecting with mesepisternomeral ridge.

Metanotum fully developed, medial groove on metanotum not distinctly longer than allocrista, metascutum larger than metascutellum. Metasternum much longer than mesosternum. Metendosternite with stalk nearly 2.5 times as long as wide, with full set of ridges, arms long and thin, tendons from stalk reach metepisternomeral ridge and hind coxa.

Elytron with maximum width near anterior $1 / 3$. Humeral callus well developed. Elytral apex obtusely angulate, surrounded by extremely narrow border. Epipleuron broad, maximum width subequal to that of mesofemur, subhorizontal, extending slightly beyond distal 3/4 of elytron, not reaching sutural margin. Lateral margin of elytron delimiting epipleuron dorsolaterally with a maximum width subequal to that of second antennomere, not reaching apical margin, visible from above except anteriorly and posteriorly. Elytral lock mechanism asymmetrical both anteriorly and posteriorly, consisting of two pairs of alternate grooves and ridges. Lock of left elytron with a shallow groove dorsally and ridge ventrally; lock of right elytron with a ridge dorsally and groove ventrally. Elytron with two sensilla patches in anterior half, basal patch larger than medial patch. Elytral base with large sensilla stripe. Sensilla stripes present near apex, sutural margin as well as lateral margin. Wings with full set of veins.

Pro- and mesotibiae without apical spine. First protarsomere in male not distinctly wider than in female. Metafemur robust with a convexity near proximal $1 / 3$ of anterior margin, posterior margin not distinctly convex. Metatibia (Fig. 4) moderately curved in dorsal view, nearly straight in lateral view; dorsal surface nearly flat in distal $3 / 4$, bearing pointed thin bristles along distal 2/5 of lateral edge; mesal edge with similar bristles along apex only, without callosity in lateral view; apical spur subequal to tarsal claw. Metatibia 2.30 times as long as first metatarsomere. First metatarsomere distally wider than proximally, ventrally flat, densely covered with thin capitate setae different from those on dorsal side, setae on proximal region of ventral side pointed; second metatarsomere shorter than first, longer than third, setae on ventral side not as dense as in first, crowded towards distal region of ventral side; third metatarsomere bilobed, setae on ventral side of metatarsomere dense, ribbon like, plumose or pointed. Claws appendiculate. 


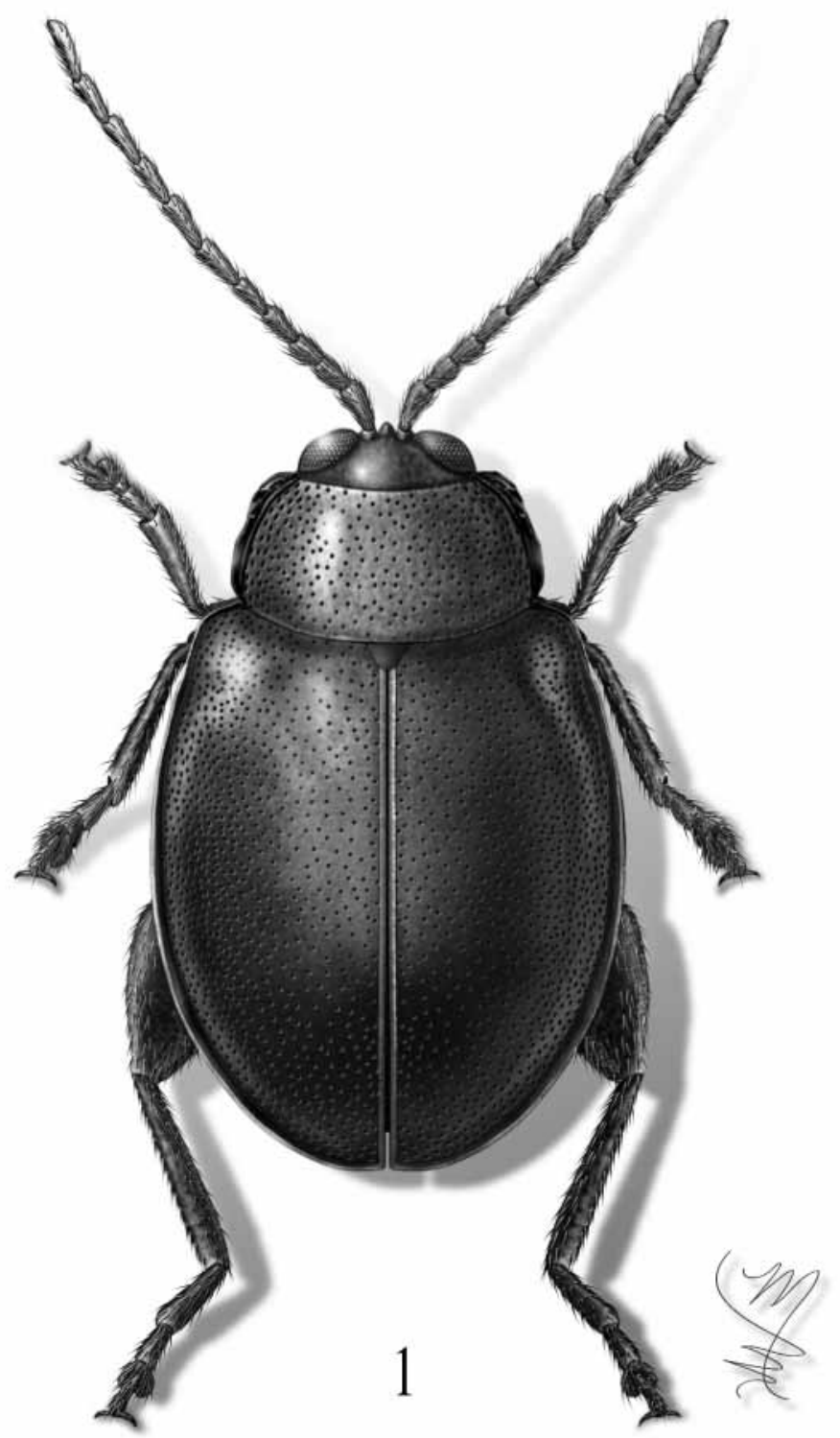

FIGURE 1. Orisaltata azurea, habitus.

Abdomen with five distinct sternites (Fig. 6). Apical sternite as long as two preceding sternites together, without appendages basally. Posterior margin of last abdominal sternite entire in female, bisinuate forming lobe in middle in male. Apical tergite of female 1.24 times wider than long, without a groove along middle, with longer setae distally, with pair of sensilla patches near anterior margin, each being nearer to spiracle than to each other. 


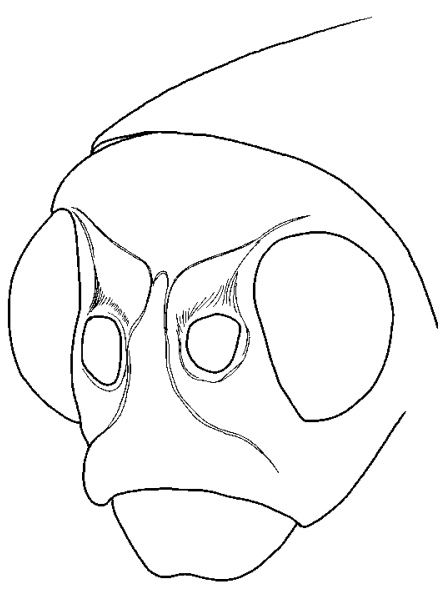

2
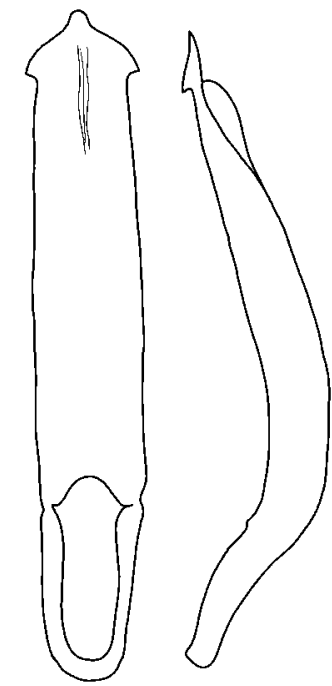

3

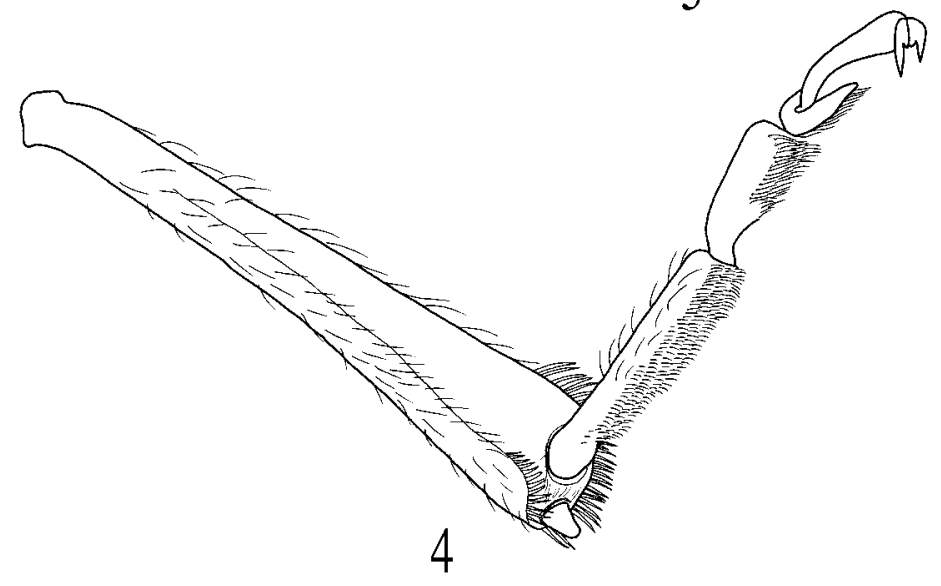

FIGURES 2-4. Orisaltata azurea; 2, head in fronto-lateral view; 3, male genitalia in ventral and lateral view; 4, left metatibia.

Spermatheca (Fig. 5) with pump well differentiated from receptacle, horizontal part of pump longer than vertical part, with tiny denticle at apex; length of receptacle slightly less than twice its width, outer side slightly concave, inner side convex. Duct originates at obtuse angle with receptacle, highly twisted and coiled, longer than receptacle. Tignum (Fig. 7) slightly curved, with a groove along middle, proximal sclerotization slightly widened, distal sclerotization Y-shaped, much wider than proximal sclerotization. Vaginal palpus (Fig. 8) with distal sclerotization longer than proximal sclerotization, membranous unsclerotized lateral area longer than proximal sclerotization but shorter than distal sclerotization; vaginal palpus slightly narrowing posteriorly. 


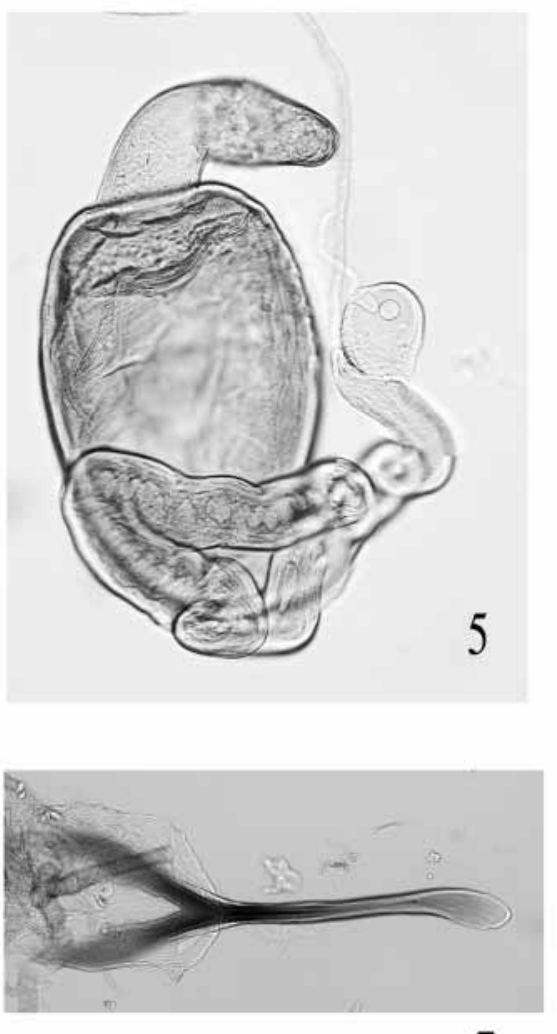

7
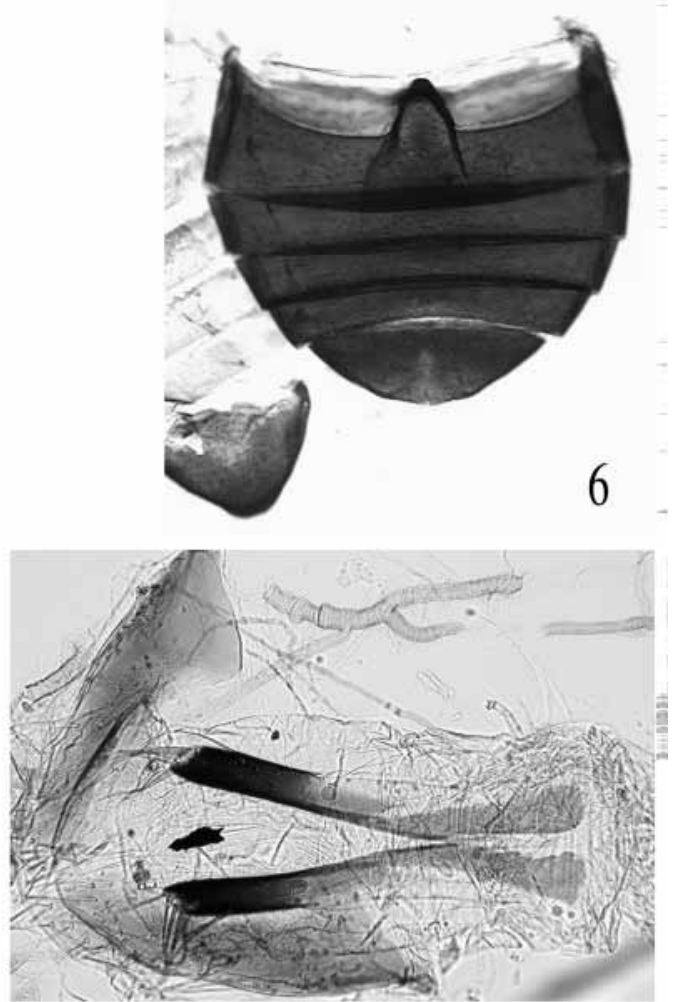

FIGURES 5-8. Orisaltata azurea; 5, spermatheca; 6, abdominal ventrites; 7, tignum; 8, vaginal palpi and internal abdominal sclerites.

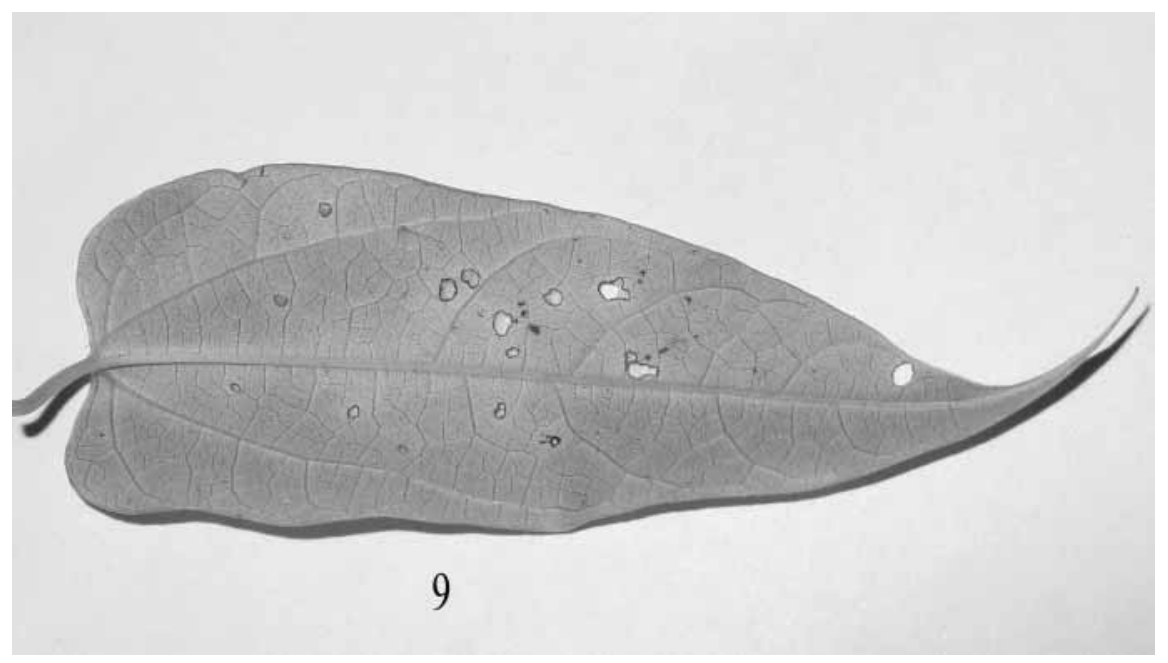

FIGURE 9. Leaf of Aristolochia indica L. damaged by adults of Orisaltata azurea. 
Median lobe of aedeagus (Fig. 3) simple, not robust, convex in lateral view; in ventral view proximal end deeply incised, apex arrowhead-shaped.

Immature stages unknown.

Type species. Aphthona azurea Jacoby, 1896

Etymology. The genus name is derived from the name of the zoogeographic (Oriental) region where the genus occurs and Latin saltatus (hopper). The name is feminine.

Biology. The host plant of Orisaltata azurea is Aristolochia indica L. (Aristolochiaceae) (Indian birth wort) (Fig. 9). Aristolochia indica is used in Ayurveda, the traditional health care system in India, for the treatment of several diseases including snake bite and cholera. Adults feed on the ventral side of leaves by scraping green tissue leading to the formation of small holes or often leave the dorsal transparent lamina intact. Beetles are apparently nocturnal as they usually come out for feeding in the afternoon and activity increases after sunset.

Discussion. Orisaltata resembles Pseudaphthona Jacoby, an endemic genus of the Nilgiri Hills in south India. Orisaltata can easily be differentiated from Pseudaphthona by the pronotum 1.6 times wider than long, intercoxal prosternal process flat on top, tibiae neither sulcate nor dilated, and lateral side of elytron without distinct post basal depression or a ridge. In Pseudaphthona the pronotum is about as long as broad, the intercoxal prosternal process is longitudinally sulcate, the tibiae are sulcate and anteriorly dilated, and the lateral side of elytron has a strong post basal transverse depression and a ridge extending posteriorly from the humerus.

Orisaltata differs from Aphthona Chevrolat by several features: the antennal calli are distinctly separated (contiguous in Aphthona), the anterior portion of the antennal calli enter into the interantennal space and are separated by the frontal ridge (antennal calli neither enter into interantennal space nor are separated by frontal ridge in Aphthona); supracallinal sulci deep and form straight line (variable and more or less curved in Aphthona); supraorbital sulcus absent (well formed in most Aphthona); orbit narrow (wide in Aphthona); anterofrontal ridge high medially as well as laterally (low laterally and medially in Aphthona); labrum with four long setae (six setae in Aphthona); lateral margin of pronotum and elytra wide (much narrower in Aphthona); mesosternum extremely wide between coxal cavities (moderately narrow in Aphthona); spermatheca with long coiling duct (duct short and not coiled in Aphthona); proximal end of median lobe of aedeagus is deeply incised in ventral view (proximal end of median lobe of aedeagus is not incised in Aphthona); dorsal opening of median lobe of aedeagus is partially covered with a pair of laminae (only single lamina is present in Aphthona); only known host plant of Orisaltata belongs to Aristolochiaceae which is uncommon for Aphthona.

\section{Orisaltata azurea (Jacoby) New combination}

Aphthona azurea Jacoby 1896: 256 (type locality: Myanmar [Burma]. Lectotype (MCZC), exam- 
ined). Maulik 1926: 367, 372 (key, redescription, taxonomic notes, distribution, deposition of type specimens). Heikertinger 1944: 114/200, 116/202 (key catalog, taxonomic notes). Scherer 1969: 69, 75 (key, distribution, synonymical bibliography). Konstantinov \& Lingafelter, 2002: 215, 216 (lectotype designation, placed under incertae sedis, synonymical bibliography, taxonomical notes).

Aphthona babai Kimoto, 2000: 37 (type locality: Thailand. Holotype (KMHJ), examined). Konstantinov \& Lingafelter, 2002: 216 (placed under incertae sedis, taxonomical notes). NEW SYNONYM.

Type material examined. Aphthona azurea: Lectotype ơ. Labels: 1) azurea Jac.; 2) Prome; 3) Jacoby $2^{\text {nd }}$ Coll.; 4) Type 18937 ; 5) Lectotype Aphthona azurea Jacoby des. A. Konstantinov, 1998 (MCZC).

Aphthona babai: Holotype +. Labels: 1) Slika Fall. Thailand 24.I.1968 Coll. K. Baba;

2) Holotype; 3) Aphthona babai Kimoto, n. sp. det. S. Kimoto, 19; 4) 20009251R37 (KMHJ).

Material examined: India: Karnataka: Bangalore - 65, University of Agricultural Sciences campus, 10 ${ }^{\star}$, 4. vi.1998, Aristolochia indica, Prathapan Coll. (PKDC); 2 우, same data except the date 5.vi.1998 (UASB) Kerala: 40*, 29, Ponmudi, 1.v.2005, Prathapan Coll.; Tamil Nadu: 3우, Burliar Hills, 25.x.2003, Prathapan Coll. (PKDC). Thailand: Lang Song U. P. April 1991, leg. Kral (20, 2 우) (USNM).

Host plant. Aristolochia indica L. (Aristolochiaceae) (Fig. 9)

Distribution. Myanmar (Prome), India (Karnataka, Kerala, Tamil Nadu), Thailand (Slika Fall).

Discussion: Comparative study of the male lectotype of $A$. azurea with males from Thailand identified as A. babai, and the female holotype of A. babai with females of $A$. azurea from India, revealed no characters to separate them. Therefore, we here synonymize A. babai Kimoto with $O$. azurea (Jacoby).

\section{Acknowledgements}

We thank M. L. Chamorro-Lacayo (University of Minnesota, St. Paul, MN), A. L. Norrbom and N. E. Woodley (Systematic Entomology Laboratory, ARS, USDA, Washington, D. C.), and A. K. Tishechkin (Department of Entomology, Louisiana State University, Baton Rouge, LA) for reviewing an earlier version of this manuscript and providing valuable suggestions. We are grateful to M. Metz (Systematic Entomology Laboratory, ARS, USDA, Washington, D. C.) for habitus drawing of O. azurea. Senior author is grateful to Dr C. A. Viraktamath for guidance and support. Senior author's work on flea beetles is partially supported by the Kerala State Council for Science, Technology and Environment, Trivandrum. 
Heikertinger, F. (1944) Bestimmungstabellen europäischer Käfer. LXXXII. Fam. Chrysomelidae. 5. Subfam. Halticinae. 2. Gatt. Aphthona Chevr. Koleopterologische Rundschau, 30 (1/3), 37/ $123-124 / 209$.

Jacoby, M. (1896) Descriptions of the new genera and species of Phytophagous Coleoptera obtained by Mr. Andrewes in India. Annales de la Société Entomologique de Belgique, 40, 250-271.

Kimoto, S. (2000) Description of some new genera and species of Chrysomelidae (Coleopetra) from Thailand, Laos, and Vietnam. Serranga, 5(1), 1-39.

Konstantinov, A.S. (1998) Revision of the Palearctic species of Aphthona Chevrolat and cladistic classification of the Aphthonini (Coleoptera: Chrysomelidae: Alticinae). Memoirs on Entomology, International, Associated Publishers, Gainesville, 429 pp.

Konstantinov, A.S. \& Lingafelter, S.W. (2002) Revision of the Oriental species of Aphthona Chevrolat (Coleoptera: Chrysomelidae). Miscellaneous Publications of the Entomological Society of Washington, Washington, DC, 349 pp.

Maulik, S. (1926) Coleoptera. Chrysomelidae (Chrysomelinae and Halticinae). In: Shipley, A. E. (ed.) The fauna of British India including Ceylon and Burma. Taylor and Francis, London. 442 pp.

Scherer, G. (1969) Die Alticinae des indischen Subkontinentes (Coleoptera - Chrysomelidae). Pacific Insects Monograph, 22. 251 pp. 